\title{
CONTEÚDO DO DIREITO AGRÁRIO: IMPLICAÇÕES DA NATUREZA DAS SUAS NORMAS, DO OBJETO E DAS FONTES
}

Marcos Prado de Albuquerque"

SUMÁRIO: 1. Introdução. 2. Generalidades. 3. Natureza pública ou privada. 4. Objeto. 5. Fontes. 6. Conclusão. 7. Bibliografia.

SUMMARY: 1. Introduction. 2. Generalities. 3. Public or private nature. 4. Object. 5. Sources. 6.Conclusion. 7. Bibliography.

SUMARIO: 1. Introducción. 2, Generalidades. 3. Naturaleza púm blica o privada. 4. Objeto. 5.Fuentes. 6. Conclusión. 7. Bibliografia.

RESUMO: O texto defende a criação de cadeira própria para o direito agrário nas universidades, em razão de sua natureza, objeto e fontes próprias, destacando ainda a necessidade de justiça agrária.

ABSTRACT: The text defends the creation of proper chair for the agrarian law in the universities, in reason of its nature, object and sources; detaching the necessity of agrarian justice.

RESUMEN: El texto defiende la creación de la silla de derecho agrario en las universidades, en razón de su naturaleza, objeto y fuentes, destacando la necesidad de la justicia agraria.

PALAVRAS-CHAVE: Direito agrário. Fontes. Objeto. Natureza jurídica. Justiça Agrária.

KEY-WORDS:Agranan law. Sources. Object Legal nature Agrarian fustice

PALABRAS-LLAVE: Ley Agraria. Fuentes. Objeto. Naturaleza legal. Justicia agraria. 


\section{Introdução}

A Constituição da República Federativa do Brasil estabelece, no seu artigo 22, que compete privativamente à União legislar sobre Direito Agrário. Qual o significado desse preceito, ou em outras palavras, o que se inclui no âmbito da expressão Direito Agrário? Diversas possibilidades de construção da resposta podem ser imaginadas. Uma delas é pelo conteúdo jusagrário. Isto é, compete privativamente à União legislar sobre tudo aquilo que componha o Direito Agrário. Além disso, o conteúdo jusagrário é fundamental para um curso, quer entendido como unidade de ensinoaprendizagem, quer entendido como livro didático, pois será a diretriz principal tanto do primeiro, quanto do outro. Por fim, não se pode esquecer a implicação que o conteúdo traz para a doutrina jurídica, uma vez que ele se constitui em área de influências recíprocas entre a legislação, a jurisprudência e os valores intervenientes no campo que delimita.

O constituinte brasileiro, ao estatuir a regra do artigo 22 constitucional, não inventou naquele momento o Direito Agrário, mas tinha em mente um contexto cultural e jurídico que lhe forneceu a idéia. Vale dizer que o constituinte, ao falar em Direito Agrário, tinha em mente um conjunto normativo existente ou por existir, mas que se delimitava de alguma forma. Assim, o conteúdo imaginado era aquele que a cultura jurídica apontava. Neste sentido, o conteúdo jusagrário deve ser buscado na doutrina agrarista.

Esta última, ao tratar do conteúdo do Direito Agrário, com frequiência, toca em assuntos que são acessórios ou complementares a ele, como, por exemplo, a natureza das normas agrárias, o objeto dessa especialização jurídica e as fontes dessa normatividade. As implicaçốes que esses tópicos trazem para o conteúdo jusagrário consistem, assim, em tema importante para a configuração desse mesmo conteúdo.

\section{Gencralidades}

Em 1943, Francisco Malta Cardoso, no Congresso Jurídico Nacional, apresenta tese reclamando a criação da cadeira de Direito Rural nas Faculdades de Direito do Brasil (Raymundo LARANJEIRA, 1999:255). Verifica-se, pois, que a necessidade de estudar o conteúdo do Direito Agrário já vem de mais de cinqüenta anos.

Uma das primeiras coisas que vão se apresentar ao estudioso do tema é a questão de um posicionamento quanto à própria existência do Direito Agrário. Partindo-se da premissa de que existe o Direito Agrário, há uma outra questão a ser resolvida: a sua autonomia ou especialidade se determina pela existência de princípios, ou pela presença de institutos? Inegável a 
importância dessa questão; todavia, como examina-se o conteúdo desse ramo ou especialização do Direito, busca-se em grande medida a delimitação dos institutos jurídicos que se encontram no seu âmbito. Logo, malgrado a relevância dessa discussão, ela pode ser deixada de lado, uma vez que tanto uma posição como outra irá redundar em resultados muito semelhantes .

O $1^{\text {a }}$ Congresso Internacional de Direito Agrário, realizado entre 25 e 29 de outubro de 1971, em PORTO ALEGRE, expediu o documento chamado "Pronunciamento de Porto Alegre", no qual expõe o conteúdo, a base do Direito Agrário, além de tratar de outros tópicos relevantes a este ramo da Ciência Jurídica. No que se refere àquelas duas partes, diz que o Direito Agrário se compõe do estatuto jurídico da propriedade da terra e da atividade agrária, e que é indispensável que o princípio da função social da terra informe esse estatuto (Igor TENORIO, 1975:6).

Corrobora a afirmação anterior Lúcio Mendieta y NUNEZZ (1966:3) quando diz: Chegamos, assim, a delimitar o conceito e o conteúdo do Direito Agrário concretando-o nas leis, regulamentos e disposiçôes administrativas referentes à propriedade rústica, à agricultura, pecuária, silvicultura, aproveitamento de águas, crédito rural, seguros agricolas, colonização e planejamento agrário. ${ }^{2}$

Logo, um dos mais claros conteúdos de Direito Agrário são, portanto, as normas, como em todo ramo jurídico, de resto.

O sistema de normas jurídicas, segundo lições elementares, é do campo ético. Ou seja, trata do dever ser comportamental. A conduta regulada por essas normas tanto é a humana quanto a institucional.

Neste sentido, o Estatuto da Terra estabelece como deve o agricultor ou empresário explorar o seu fundo, como deve ser organizada a empresa e quais os fins a serem perseguidos pelo poder público.

Estas normas podem ser encaradas como um discurso que trata de uma situação ideal almejada por um determinado grupo. Se este querer social se reveste do aspecto jurídico, passa a ter efetividade e perenidade, que a ação e as idéias, sem base jurídica, não têm. E mais, a norma tem um caráter dogmático que advém da aceitação e da coesão sociais que provoca.

\footnotetext{
' A questão é, efetivamente, de grande importância. A doutrina jusagrarista brasileira é de quase unarimidade a favor da tese dos principios como fundamentais para a existencia do Direito Agrátio. Entretanto, não se pode deixar de teconhecer que a doutrina jusagrarista estrangeira possit uma Fortissima corrente a favor do estudo do Direito Agránio através de seus institutos. Sobre esta ultima, pode-se recorrer a Antonio CARROZZA (1974).

${ }^{2}$ Traduçäo realizada neste trabalho, no original: "Llegamos, ast, a delimitar el concepto y el contenido del Derecho Agrario concretandoto a las leyes, reglamentos y disposiciones administrativas referientes a la propriedad rústica, a la agricultura, ganaderia, silvicultura, aprovechamiento de aguas, credito rural, seguros agricolas, colonización y planificación agraria" (NUNEZ, 1966:3).
} 
A natureza da norma de Direito Agrário sempre foi motivo de grande discussão. É pública ou privada, ou será ainda uma combinação funcional de ambas?

\section{Natureza pública ou privada}

A classificação do direito objetivo em público e privado, como se sabe, vem de Roma, através de Ulpiano. O Direito público, como sendo aquele que interessasse à República, e o privado, à utilidade dos particulares. Embora a divisão tivesse se desenvolvido na sua teoria, com o passar do tempo, atualmente já se rarefazem os limites entre um e outro.

Existem os que observam no Direito Agrário pleno caráter público, como Villar-Romero, fundando-se na imposição de deveres subjetivos públicos para o proprictário do prédio rústico por motivos de utilidade geral e a favor da sociedade; e há os que the dão caráter privatístico, a exemplo de Casals Coldecarrera, o qual se embasa, contudo, apenas na afirmativa solta de que as instituições, direitos reais e relações obrigatórias agrárias possuem substantividade inarredável do direito privado (LARANIEIRA, 1975:125).

A maioria dos doutrinadores prefere lhe dar um caráter misto. Dentre esses, há os que apontam a prevalência de normas de Direito privado, como Zulueta; outros que ressaltam a prevalência das normas de Direito público, como Palermo e Marcial. Finalmente, há aqueles que the dão uma bivalência de suas regras como característica; aqui se encontram Temistocles Cavalcanti e LARANJEIRA (1975:125s).

LARANJEIRA (1975:129ss), concordando com a natureza mista das normas do Direito Agrário, discorda da bivalência nos termos propostos por Cavalcanti. Para ele, apoiado nas teorias sobre a natureza do Direito do Trabalho, as normas públicas e privadas no Direito Agrário são inter-relacionadas e interdependentes, constituindo um conjunto univalente de miscigenação.

Isto significa, portanto, que as suas normas, de uma espécie como da outra, perdem as suas características próprias para ganharem outra diferente. Esse novo status é o econômico-social, aliás, como o Direito do Trabalho.

São ramos do Direito que surgiram em razão da necessidade premente da intervenção do Estado na vida econômica e social e que se desenvolveram com a expansão da doutrina Keynesiana.

Assim, tem-se, nesta nova categoria do direito objetivo, o Direito do Trabalho, o Direito Agrário, o Direito Bancário etc. 
Poder-se-ia, ainda, fazendo alusão ao pensamento expresso por José Alcebíades de OLIVEIRA JÚNIOR (2000:102s) sobre os novos direitos, perguntar: O Direito Agrário, como um Direito que exige a participação do Estado, a atuação do Estado, não seria um Direito de segunda geração?

O Direito Agrário, através de sua doutrina, jurisprudência e normas, revelase um direito de natureza econômico-social, pois tem um caráter ao mesmo tempo público e privado e trata de relações de produção. São seus objetivos o fomento à produção agrária, concomitantemente com a preservação dos recursos naturais renováveis e bem-estar social da comunidade rural.

Assim, são características do Direito Agrário a natureza de suas normas que são tuitivas, no dizer de Antonino C. VIVANCO (1967:191), que se manifesta, de modo notável, na tendência de defender e proteger tanto o fator humano quanto o natural no meio rural. Os interesses econômicos e sociais, protegidos pelas suas normas, são determinados pelo ciclo biológico, característico da produção agropecuária.

Da mesma maneira, Antonio Villabon diz: Direito Agrícola significa todas aquelas normas de ordem legal, relacionadas direta e imediatamente com o aprovertamento do campo mediante o cultivo da terra. ${ }^{3}$

Todos esses fatores, e a função social da propriedade, que é o fundamento do próprio Direito Agrário, revelam o seu posicionamento econômico-social, vez que esse princípio se inclui nas constituições modernas com o objetivo de legitimar a ação estatal, como agente promotor, no campo social e econômico.

É assim que vem estabelecido na Constituição brasileira, no Título VII, que trata da Ordem Econômica e Financeira: Art. 170 - A ordem econôtmica, fundada na valorização do trabalho humano e na livre iniciativa, tem por fim assegurar a todos existência digna, conforme os ditames da justiça social, observados os seguintes princípios: (...); III - função social da propriedade; (... $)^{4}$.

Indica Artur Pio dos SANTOS NETO (1979:46) que o Direito Agrário é um Direito econômico, pois está estreitamente ligado aos objetivos do desenvolvimento econômico, às normas fundamentais da justiça social e aos fins precípuos do Estado: a promoção, o bem-estar e o progresso econômico social do Homem como unidade (pessoal e familiar).

Em decorrência do acima, tem-se que o Direito Agrário é um ramo jurídico

\footnotetext{
ApUd LARANJEIRA (1975:59).

- BRASIL Constituiça da Repubitca Federativa do Brasil. Promulgada em 5 de outubro de 1988. In: LOPES, Maurício Antonio Ribeiro (coord.). Constituição federal. 6. cd. rev. e atual. São Paulo: Editora Revista dos Tribunais, 2001, p. 1-134. Todas as demais citaçöes do texto constitucional terăo esta fonte.
} 
finalista, pois a decomposição do princípio da justiça social, quando aplicado no campo, leva à elaboração dos seguintes objetivos gerais: o aumento da produtividade, a conservação dos recursos naturais e o bem-estar e progresso socioeconômico dos seus agentes (LARANJEIRA, 1975:63).

Pode-se dizer que se constitui de regras de origem civil, a que se superpõem regras de caráter público, as quais traduzem, mais das vezes, a política agrária imperante (TENÓRIO, 1975:5).

O Direito Agrário toma a direção do Direito Público, visto que os seus preceitos são, em sua maioria, limitadores da vontade, baseados na irrevogabilidade das normas legais pelo acordo de vontades.

Tơda disciplina jurídica do tipo econômicosocial tem essa ambivalência na qualificação das suas normas em públicas ou privadas. O mesmo ocorre com o Direito Agrário.

É o que se vê quando A. Ballarín MARCIAL (1965:382) explica a sua definição: creio que, ao falar de normas especialmente destinadas, indico tanto as normas de Direito público como as de Direito privado...

Na mesma situação encontra-se SANTOS NETO (1979:47), quando expõe: O Direito da Economia ou os Direitos Sociais caracterizam-se pelo seu aspecto ambivalente. Ao mesmo tempo que surgem da intensa revolução nos processos, métodos e sistemas técnicos dos nossos dias, servem, também, para promovê-la, impondo modificações e mudanças.

Por serem as suas normas finalistas. - pretendem a realização de una política - e com caráter ambígüo - públicas e privadas -, pode-se classificar o Direito Agrário como pertencente ao campo jurídico das disciplinas econômico-sociais.

Expõe VIVANCO (1967:22) os princípios fundamentais para determinar a área de incidência das normas agrárias. Segundo ele, essa qualidade de normas é aplicável à atividade agrícola e ainda à transformadora e à comercial, estas duas últimas como complemento da produtiva. A industrial ou comercial que não for complementar da agrária, mas tiver importância para o desenvolvimento desta, deve ser regulada pelas normas agrárias. Por fim, incluem-se todas aquelas que, não sendo produtivas, estâo relacionadas estreitamente com estas.

\section{Objeto}

Todos esses elementos são objeto do Direito Agrário. Talvez esse o motivo pelo qual Antonio CARROZZA (1988) não fala diretamente do conteúdo, mas implicitamente considera que o conteúdo será o objeto. 
CARROZZA (1988:157s) adiciona ainda aquilo que chama de dinâmica do objeto, baseando-se no fato de que a evolução da realidade social e econômica, assim como a dos ordenamentos juridicos, vêm impondo uma expansão do objeto do jusagrarismo, via atendimento das necessidades de proteção, fomento e subvenção da empresa agrária e da atividade agrária nos mais variados aspectos, nomeando esse procedimento como medidas conservativas da empresa agrícola. A propósito destas, diz: Vasta e variegada é a gama das medidas e dos meios de conservação, e conseqüentemente dos institutos jurídicos que daí são a resultante, (...): neste campo as especificaçôes operam continuamente, e o agrarista não pode ignorá-las só porque tratar-se-iam de estruturas que debordam do conceito, na verdade bastante modesto, que tradição e praxe assinalam como objeto do Direito Agrário e que portanto vêm convencionalmente englobadas no objeto de outras especialidades do Direito ${ }^{6}$. Percebe-se, destarte, que o objeto é historicamente delimitado.

O objeto do Direito Agrário pode ser apontado como sendo a produção agrária. Esta, por sua vez, pode ser entendida estática ou dinamicamente. $\mathrm{Na}$ primeira acepção, resumidamente, estar-se-ia diante do resultado do processo produtivo agrário. No outro sentido, é compreendida como o próprio processo produtivo do agro que engloba três grandes aspectos: a estrutura agrária, a atividade agrária e a política agrária. Pode-se, assim, dizer que o objeto do Direito Agrário consiste nesses aspectos mencionados ${ }^{7}$.

Alcir Gursen de MIRANDA (1989:65) distingue conteúdo de objeto, lecionando:... o objeto é o que é disciplinado e o conteúdo é o que disciplina; o objeto é o normatizado e o conteúdo são normas jurídicas.

\section{Fontes}

Em outra oportunidade, Antonio CARROZZA e Ricardo Zeledón ZELEDÓN (1990:73) vão reafirmar a vinculação do conteúdo com o objeto e adicionar que o primeiro se vincula, também, com o sistema de

\footnotetext{
"Traduça realizada neste trabalho, no original: "Vasta quanto varia è la ganma delle misure e dei mezzi di conservazione, e conseguentemente degli istituti giuridici che ne sono la risultante, $(. .$.$) in$ questo campo le specificazioni operano a getto continuo e l'agrarista non può ignorarle solo perché si trattarebbe di rilevar struture che debordano dal concetto, invero abbastanza modesto, che tradizione e prassi assegnano all'oggetto del d.a e che pertanto vengono convenzionalmente fatte ricadere nell'oggetto di altre specialità del diritto."(CARROZZA, 1988:158)

"A proposito desta fortma de se ver o objeto do Direito Agrário, confira Marcos Prado de ALBUQUERQUE (1984:22-35).
} 
fontes do Direito Agrário. A posição de ambos é, resumidamente, a de que nas situações em que o conteúdo não se encontre positivado, principalmente como um direito próprio, ele deve ser buscado de outra forma. O instrumento possível seria um sistema de fontes adequado.

Talvez seja a situação brasileira, uma vez que alguns autores consideram - Direito Agrário brasileiro não consolidado, como expressa Ismael Marinho FALCÃO (1995:50): Para a sua solidificação[do Direito Agrário], como dito antes, resta-nos apenas esperar que ao lado da autonomia legislativa e da autonomia didática, surja a tão desejada e necessária autonomia jurisdicional, que somente será alcançada no dia em que for criada a justiça agrária destinada a conhecer ejulgar os litigios decorrentes da aplicação das leis agrárias, desafogando, conseqüentemente, os escaninhos da Justiça Federal e, mais das vezes, a própria Justiça Estadual.

Indubitavelmente, a presença de uma justiça agrária traria uma explicitação maior do conteúdo do Direito Agrário, via matérias da competência dessa justiça especializada. Todavia, tanto a evolução da doutrina jusagrarista, quanto a previsão constitucional, a legislação e a jurisprudência, todas brasileiras, fornecem elementos seguros referentes a determinados institutos jurídicos, como exclusivamente agrários. De forma que, no caso do Brasil, poder-se-ia adotar o método adequado para os casos de conteúdos positivados.

\section{Conclusão}

Da exposição feita, podem-se deduzir algumas reflexões com relação aos citados tópicos acessórios, postos pela doutrina jusagrarista ao tema conteúdo do Direito Agrário.

Quanto à natureza das normas jurídicas agrárias, chega-se à conclusão de que tanto considere-se que ela tenha uma natureza privada, quanto uma natureza pública, quanto uma do terceiro tipo - econômico social - , ela não terá relevância para a delimitação do conteúdo. Isto é, nenhuma norma jurídica, nenhum instituto jurídico, poderá ser excluído ou ser computado no conteúdo do Direito Agrário, por ser norma ou instituto privado, norma ou instituto público, norma ou instituto de uma natureza de um terceiro tipo. Vale dizer que a natureza jurídica das normas de Direito Agrário não tem implicação alguma na configuração do conteúdo jusagrário de um determinado ordenamento.

O contrário pode ser observado com relação ao objeto. Uma das possíveis 
compreensões do conteúdo jusagrário o conceitua como as normas que regulam o objeto, que disciplinam o objeto do Direito Agrário. Entendido esse objeto como a produção agrária, e esta como uma dinâmica que envolve a estrutura agrária, a atividade agrária e a política agrária, o conteúdo do Direito Agrário será a normatividade que disciplina ou regulamenta essa estrutura, atividade e política agrárias. Estas são historicamente determinadas, uma vez que são dependentes da evolução econômica, social, cultural e tecnológica da sociedade produtora do ordenamento jurídico considerado. Assim, a configuração ou delimitação do conteúdo do Direito Agrário está estreitamente vinculada ao seu objeto, que pode ser tomado diretamente como a estrutura, a atividade e a política agrárias.

Quanto às fontes do Direito Agrário e à sua repercussão na configuração do conteúdo, a posição, que se extrai, é a de que elas podem ter influência, como elas podem não ser condicionantes. Elas podem ter repercussão naqueles ordenamentos em que não há referência a um direito próprio, a um direito especial, o Direito Agrário. Não é o caso brasileiro, pois a própria Constituição, como se viu no início deste artigo, faz mençăo ao Direito Agrário. Assim, o estabelecido no Título VII, Capítulo III, da Constituição brasileira tem inegável repercussão na configuração do conteúdo jusagrário, já que os institutos jurídicos, instrumentos e ações que daí são extraídos, certamente, fazem parte do conteúdo do Direito Agrário Brasileiro. Evidentemente que se admitem outros conteúdos, que não estão previstos em sede constitucional, mas, nesta situação, serão outros critérios que fornecerão elementos para essa consideração. A fonte constitucional, no ordenamento jurídico agrário brasileiro, fornece um mínimo de conteúdo.

Assim, as normas juridicas que disciplinem a estrutura, a atividade e a política agrárias são conteúdo do Direito Agrário Brasileiro, independentemente de ter natureza jurídica pública ou privada, sendo obrigatoriamente consideradas como jusagrárias as normas ou iustitutos que promanem dos preceitos constitucionais brasileiros contidos no Título VII, Capítulo III da Constituição federal.

\section{BIBLIOGRAFIA}

ALBUQUERQUE, Marcos Prado de. Direito agrário: um estudo sobre cooperativismo rural. Dissertação apresentada ao Departamento de Ciências Jurídicas da Pontificia Universidade Católica do Rio de Janeiro PUCRJ como parte dos requisitos para obtenção do título de Mestre em Ciências Jurídicas: Direito e Desenvolvimento. Rio de Janeiro: Mimeo, 1984. 
CARROZZA, Antonio. Lezioni di diritto agrario: I - elementi di teoria generale. Milano: Giuffrè Editore, 1988.

CARROZZA, Antonio. L'individuazione del diritto agrario per mezzo dei suoi istituti. Estratto dalla Rivista Di Diritto Civile Anno XX - 1974 - n. 6 - Parte Prima. Padova: CEDAM, 1974.

CARROZZA, Antonio \& ZELEDÓN, Ricardo Zeledón. Teoría general e institutos de derecho agrario. Buenos Aires: Editorial Astrea de Alfredo y Ricardo Depalma, 1990.

FALCÃO, Ismael Marinho. Direito agrário brasileiro: doutrina, jurisprudência, legislação e prática. Bauru: EDIPRO, 1995.

LARANJEIRA, Raymundo. Odireito agrário como ciência no Brasil. In: LARANJEIRA, Raymundo (Coordenador). Direito agrário brasileiro: em homenagem à memória de Fernando Pereira Sodero. São Paulo: LTr., 1999, p. 251-293.

LARANIEIRA, Raymundo. Propedêutica do direito agrário. São Paulo: LTTr, 1975. MARCIAL, A. Ballarín. Derecho agrario. Madrid: Editorial Revista de Derecho Privado, 1965.

MIRANDA, Alcir Gursen de. Teoria de direito agrário. Belém: CEJUP, 1989. NUÑEZ, Lúcio Mendieta y. Introducción al estudio del derecho agrario. 2. ed. México: Editorial Porrúa, 1966.

OLIVEIRA JÚNIOR, José Alcebíades de. Teoria jurídica e novos direitos. Rio de Janeiro: Editora Lumen Juris, 2000.

SANTOS NETO. Artur Pio dos. Instituiçōes de direito agrário. Recife: Universidade Federal de Pernambuco - Editora Universitária, 1979.

TENÓRIO, Ígor. Manual de direito agrário. São Paulo: Ed. Resenha Universitária, 1975.

VIVANCO, Antonino C. Teoria de derecho agrario. V. I. La Plata: Ediciones Librería Jurídica, 1967. 